\title{
Interfaces entre a Linguística e a Literatura: um estudo de Madame Bovary
}

\author{
Renata Aiala de Mello*
}

\section{Resumo}

Literatura e Linguística são duas disciplinas que, historicamente, foram tratadas de maneira separada. Hoje, aparentemente, há um reconhecimento recíproco por parte dos estudiosos de cada área. Com este trabalho, mostramos algumas interfaces possíveis entre os estudos linguísticos e os estudos literários, através de uma análise discursiva do romance Madame Bovary, de Gustave Flaubert (1856, 1951). Com o arcabouço teórico da $\mathrm{AD}$, delineamos as imagens de si (ethos) da personagem principal, Emma Bovary. Além disso, com o auxílio do quadro comunicacional da Semiolinguística de Patrick Charaudeau (1983), contextualizamos o romance e seu discurso na sociedade francesa do século XIX, fazendo, assim, uma análise pluridisciplinar da obra.

Palavras-chave: Linguística. Literatura. Análise do Discurso. Interfaces. Madame Bovary.

* Universidade Federal da Bahia. (UFBA). Professora efetiva de língua, literatura e cultura francesa e francófona da Universidade 


\section{Interfaces entre la Linguistique et la Littérature : une étude de Madame Bovary}

\section{Résumé}

La Littérature et la Linguistique sont deux disciplines qui, historiquement, ont été étudiées séparément. Aujourd'hui, apparemment, il y a une reconnaissance mutuelle de la part des chercheurs dans chaque domaine. Avec ce travail, on montre quelques interfaces possibles entre les études linguistiques et les études littéraires à travers une analyse discursive du roman de Gustave Flaubert, Madame Bovary (1856, 1951). Avec le cadre théorique de l'Analyse du Discours, nous avons esquissé les images de soi (ethos) du personnage principal, Emma Bovary. De plus, à l'aide du cadre communicationnel de la Semiolinguistique de Patrick Charaudeau (1983), on contextualise le roman et son discours dans la société française du $\mathrm{XIX}^{\mathrm{e}}$ siècle, réalisant ainsi une analyse multidisciplinaire de l'œuvre.

Mots-clés : Linguistique. Littérature. Analyse du Discours. Interfaces. Madame Bovary.

Recebido em: 15/03/2020

Aceito em: 20/05/2020 


\section{Introdução}

Para os analistas do discurso hoje, as Ciências Humanas, Sociais e da Linguagem mostram que não há (ou não deveria haver) um objeto de estudo reservado a uma só disciplina. Cada uma propõe uma visão que lhe é própria, uma perspetiva, um aclaramento particular sobre um determinado corpus. Uma disciplina não é melhor, mais poderosa do que a outra, mas se completam e se complementam, buscam afinidades para auxiliar nas interpretações e análises.

Entretanto, nem sempre a interdisciplinaridade foi bem vista na academia. Machado (2003) vê, com preocupação, os riscos de segregação entre a Análise do Discurso e a Literatura. Isso porque as relações entre o texto de ficção e a Análise do Discurso provocam dúvidas ou discussões por parte de alguns estudiosos que insistem em não aceitar nenhum tipo de abordagem de textos literários que tenha suas bases na Linguística. Charaudeau, por sua vez, acredita que há, atualmente, entre a Linguística e a Literatura, uma reaproximação, uma relação de confluência na qual a disciplina teórica percebe a Literatura como uma manifestação da linguagem e a trata como tal:

As Ciências Humanas e Sociais modernas nos ensinam que não há objeto de estudo reservado a uma só disciplina, e que cada uma propõe um aclaramento particular que lhe é próprio, sobre o objeto analisado. Mas elas nos ensinam, ao mesmo tempo, que nenhuma dessas disciplinas pode ignorar as outras, que é preciso considerar nelas as afinidades para alargar ainda mais o campo das interpretações. Nenhuma dessas disciplinas deve abjurar-se, cada uma guardando sua autonomia. Mas nenhuma pode, doravante, acreditar-se toda poderosa. Entramos na era de uma interdisciplinaridade fecunda. (CHARAUDEAU, 2005, p. 16) 
Com base nas opiniões de Machado (2003) e de Charaudeau (2005), reafirmamos que o instrumental teórico próprio da Análise do Discurso pode ser aplicado a diversos e diferentes objetos sociais resultantes da interação linguageira, incluindo, evidentemente, os textos ficcionais, literários, biográficos, críticos, dentre outros. Não nos é possível pensar que essa disciplina não se interesse, por exemplo, pela análise dos resultados de uma prática discursiva das mais antigas do mundo: a literária (MELLO, 2005a). Vemos que há, assim, um interesse crescente em trabalhar com manifestações literárias numa perspetiva que não exclui um olhar vindo da Linguística.

O texto literário deve, desse modo, ser visto como um espaço de produção discursiva e pode servir como objeto de estudo tanto para os estudos linguísticos quanto para os literários, através de pesquisas interdisciplinares. Barthes afirma que "a literatura e a linguagem estão em vias de reencontro [...] a linguagem não pode ser considerada como um simples instrumento, utilitário ou decorativo, do pensamento" (1987, p. 19-20). O autor lembra bem que "Jakobson deu um belíssimo presente à literatura: a linguística.” (BARTHES, 1987, p. 147). Ainda sobre a relação da Linguística com a Literatura, ele vê que essa é "não um corpo ou uma sequência de obras, nem mesmo um setor de comércio ou de ensino, mas o grafo complexo das pegadas de uma prática: a prática de escrever." (1978, p. 16-17). Jakobson, na mesma linha de raciocínio, afirma que "um linguista surdo à função poética da linguagem e um especialista de literatura indiferente aos problemas linguísticos e ignorante dos métodos linguísticos são, um e outro, flagrantes anacronismos." (1975, p. 161-162). Por fim, Fiorin também chama a atenção para a interdisciplinaridade entre a Linguística e a Literatura: 
De um lado, um literato não pode voltar as costas para os estudos linguísticos, porque a literatura é um fato de linguagem; de outro, não pode a linguística ignorar a literatura, porque ela é a arte que se expressa pela palavra; é ela que trabalha a língua em todas as suas possibilidades e nela condensam-se as maneiras de ver, de pensar e de sentir de uma dada formação social numa determinada época. (FIORIN, 2005, p. 7)

Diante do que pensam esses intelectuais, é plausível dizer que o discurso literário pode ser entendido como uma prática que explicita um trabalho intencional com a linguagem, elaborado por um sujeito situado num contexto cultural específico, numa dada conjuntura contextual, como apregoa Maingueneau

Ao falar, hoje, de discurso literário, renunciamos à
definição de um centro ou um lugar consagrado. As
condições do dizer atravessam o dito, que investe suas
próprias condições de enunciação (o estatuto do escritor
associado ao seu modo de posicionamento no campo
literário, os papéis ligados aos gêneros, a relação com
destinatário construída através da obra, os suportes
materiais, os modos de circulação dos enunciados...
Grifos do autor) (MAINGUENEAU, 2005, p. 17-18)

Parafraseando Mello (2005b), estamos convictos de que trabalhar com Literatura sob a perspetiva da Análise do Discurso é não só possível, mas legítimo e real. A Análise do Discurso pode e deve abordar textos literários com seu instrumental teórico e transpor, com esse gesto, o que seria a existência de uma fronteira disciplinar, acadêmica entre a Literatura e a Linguística.

Assim, através uma análise discursiva do romance Madame Bovary, de Flaubert, mostramos que é possível a interface entre os estudos linguísticos e os estudos literários. Valendo-nos do instrumental teórico da Análise do Discurso para nos apoiar e 
dar sustentação a nossas reflexões, utilizamos, como suporte, os estudos de Charaudeau, sobretudo, o quadro relativo aos sujeitos do discurso componentes do ato de linguagem e os estudos sobre a imagem de si (ethos). ${ }^{1}$ Também dialogamos com Amossy e Maingueneau, tendo em vista que esses autores tratam, entre outras coisas, de questões relativas ao sujeito da enunciação e à enunciação dos sujeitos. São estudiosos que consideram o fenômeno das interações verbais incluídos em uma problemática que leva em conta o sujeito inserido em um contexto social, ou seja, eles não se atêm apenas aos aspectos linguísticos em si, mas levam em consideração também os aspectos extralinguísticos, observam tanto as relações histórico-culturais como, por exemplo, os posicionamentos intersubjetivos dos indivíduos, como os fatores psicossociais que participam da construção dos sentidos. Com essa abordagem interdisciplinar, buscamos (re) construir a imagem de si de Emma Bovary no contexto da vida literária de sua época, com sua linguagem e sua inserção no pensamento cultural da época.

\section{Um estudo linguístico-literário de Madame Bovary}

Aopropormo-nos a pesquisar os discursos que uma sociedade produz, somos levados a perceber quais são os imaginários sociais expressos nesses discursos (CHARAUDEAU, 2009). Sob este viés, buscamos analisar Madame Bovary enquanto discurso social, por acreditarmos que ele contribui para a formação das identidades sociais, dos ethé dos indivíduos, sejam eles reais ou ficcionais e da obra literária. Analisar o romance é

Deixamos registrado que consideramos as noções de ethos e a de imagem de si como sinônimos, tomando uma pela outra sem distinção. 
também observar, através das representações que os constituem, a sociedade na qual sujeitos e obra se inserem.

Tanto as imagens de si de Flaubert quanto as do romance Madame Bovary e de sua protagonista, Emma Bovary, são construídas no/pelo romance. Entretanto, essa construção não é somente responsabilidade dessas três instâncias. Comentários e reflexões feitas por outras pessoas também contam. Temos alguns leitores ilustres (da vida e da obra) de Flaubert, que compõem parte das instâncias destinatária e interpretante de todo esse processo comunicacional.

Entendemos que no corpus acionam-se procedimentos particulares de construção da imagem de si em função de certos propósitos como, por exemplo, a apresentação (e a representação) de si e do outro, o interlocutor, além do estabelecimento de particularidades na relação entre as instâncias. Nesse sentido, consideramos que a construção da imagem de si das/nas instâncias enunciativas depende tanto das restrições impostas quanto das possibilidades oferecidas pelos discursos. Essa metodologia de análise é fundamental, visto que trabalhamos com instâncias enunciativas distintas e envolve textos e discursos variados que perpassam o romance.

Vemos como se dá a (re)constituição dos ethé da personagem Emma Bovary, feita por uma multiplicidade de vozes, que vai desde a da própria personagem, como as de outras personagens do romance, até o próprio Flaubert, além daqueles que se debruçaram sobre a obra do autor. Damos ênfase aos perfis mais recorrentes de Emma, como, por exemplo, os de leitora romântica, provinciana, mãe, esposa, doente, religiosa, burguesa e adúltera. 


\subsection{Um breve percurso teórico}

Tendo em vista que o ethos está presente em praticamente todos os discursos, ele constitui objeto de investigação de parte das pesquisas em Análise do Discurso. Ao estudar a noção de ethos, os analistas do discurso geralmente retomam, em parte ou no todo, guardando semelhanças ou propondo disjunções, a trilogia aristotélica, qual seja: o ethos, centrado no caráter, na retidão moral do orador; o pathos, ligado ao auditório, a sua sensibilização; e o $\operatorname{logos}$, atrelado ao próprio discurso, ao que ele demonstra ou parece demonstrar. Evidentemente, essas três noções têm sido retomadas não exatamente como foram concebidas pela retórica clássica, mas (re)adaptadas, (re)contextualizadas para darem conta das novas situações de comunicação, das complexidades próprias da atualidade e dos avanços proporcionados pelas pesquisas.

Amossy, no Dicionário de Análise do Discurso organizado por Charaudeau e Maingueneau registra que ethos é:

[...] a imagem de si que o locutor constrói em seu discurso para exercer uma influência sobre seu alocutário. Essa noção foi retomada em ciências da linguagem e, principalmente, em análise do discurso, em que se refere às modalidades verbais da apresentação de si na interação verbal. [...] Adquire em Aristóteles um duplo sentido: por um lado, designa as virtudes morais que garantem credibilidade ao orador, tais como a prudência, a virtude e a benevolência [...]; por outro, comporta uma dimensão social, na medida em que o orador convence ao se exprimir de modo apropriado a seu caráter e a seu tipo social [...]. Nos dois casos, trata-se da imagem de si que o orador produz em seu discurso, e não de sua pessoa real. (AMOSSY, 2004, p. 220-221 - Grifos nossos) 
O ethos não é uma representação estática e tampouco (de)limitada, mas uma forma dinâmica, construída no e pelo discurso e em co-participação com o destinatário. Para Maingueneau (2008), ao analisar a imagem de si, é preciso levar em consideração as experiências sensíveis dos discursos que mobilizam as afetividades dos sujeitos, que trazem em si índices que vão desde a escolha do registro da língua e das palavras até o planejamento textual, passando pelo ritmo, pelo corpo.

Ainda para o autor, em linhas gerais, a construção do ethos é, fundamentalmente, um processo interativo, produzido em situações comunicativas específicas, não correspondendo, necessariamente, à imagem do locutor exterior à sua fala. Maingueneau (2008) alerta que para trabalhar com a noção de ethos, hoje, é preciso realizar um duplo deslocamento: o primeiro é se afastar de preocupações psicologizantes e voluntaristas quando se analisa as instâncias enunciativas; o segundo é que se deve levar em conta a noção de ethos como transversal à oposição entre o oral e o escrito.

\section{As imagens de si de Emma Bovary}

Selecionamos um total de sete perfis de Emma mais recorrentes que delineiam a imagem de Emma Bovary: leitora romântica, provinciana, familial, doente, religiosa, burguesa e adúltera. Cabe ressaltar que esses adjetivos e substantivos não comportam a totalidade dos ethé de Emma e não são tampouco excludentes entre si. Ressaltamos que a imagem de si de Emma Bovary é construída por ela própria, enquanto sujeito enunciador e também por terceiros, que a leram e a forjaram nessas leituras. Esses ethé construídos por outros são, na verdade, efeitos de 
sentido produzidos a partir de, ou melhor, pelo próprio ethos dito ou mostrado da personagem. Dito de outra maneira, temos, como parâmetro, na composição das seções que se seguem, os vários ethé de Emma Bovary já cristalizados por ela própria e também por outras personagens, por Flaubert e por alguns críticos e estudiosos de Madame Bovary.

\subsection{Ethos de Emma leitora romântica}

Compagnon assevera que "a leitura tem a ver com empatia, projeção, identificação [...] o leitor aplica o que lê à sua própria situação [...] seu objetivo é menos compreender o livro do que compreender a si mesmo através do livro" (2003, p. 139-164). Esse parece ser, inclusive, o caso de Emma, que, ao ler, cristaliza sua relação com o mundo, com os outros, e, sobretudo, consigo mesma: “Emma ne pouvait s'imaginer à présent que ce calme où elle vivait fût le bonheur qu' elle avait rêvé." (FLAUBERT, 1951, p. 327)²

Suas leituras de romances, revistas e jornais são decisivas na composição de seu ethos. Há uma relação especular entre Emma e aquilo que ela lê. A personagem mantém um elo entre o passado e o futuro concentrado no presente da leitura. Ela entra, então, em uma ordem temporal distinta, não só porque o mundo lido não lhe é contemporâneo mas, sobretudo, porque, ao ler, ela se remete a um passado e a um futuro que são antes de mais nada o da própria leitura e não o da própria vida: leitura interrompida, suspensa pelo tempo da vida, o que a leva ao risco de uma fragmentação. Mas, a cada leitura, a

2 Ema não podia convencer-se agora de que aquela tranquilidade em que vivia fosse a felicidade que ela havia sonhado. (FLAUBERT, 1970, p. 36) 
cada retomada, a continuidade é restabelecida. Ler é, assim, para Emma, projetar-se em um tempo outro, tempo suspenso, entrecortado.

Há, nas leituras de Emma, um desejo erótico no qual o mundo inteiro é abolido, as emoções do corpo estão presentes, mescladas; mundo imaginário, suspenso, de fruição e de volúpia para o qual ela é deportada, onde ela se abisma, se perde. Esse tipo de leitura, para Barthes, é: "não é um gesto parasita [mas] um trabalho de linguagem [...] é uma nomeação em devenir" (BARTHES, 1992, p. 44-45). São leituras intensas, que suspendem o tempo e a vida da personagem, a transportam para lugares que lhe possibilitem escapar de sua realidade. Flaubert delineia esses ethé de Emma leitora romântica no próprio romance:

Elle avait lu Paul et Virginie et elle avait rêvé la maisonnette de bambous, le nègre Domingo, le chien Fidèle, mais surtout l'amitié de quelque bon petit frère [...] Elle aurait voulu vivre dans quelque vieux manoir, comme ces châtelaines au long corsage qui, sous le trèfle des ogives, passaient leurs jours, le coude sur la pierre et le menton dans la main, à regarder venir du fond de la campagne un cavalier à plume blanche qui galope sur un cheval noir. (FLAUBERT, 1951, p. 323-325). ${ }^{3}$

Emma deseja, através das leituras que faz, tudo o que ela não tem. Para alguns críticos, a literatura é um veneno para Emma, tão forte e nocivo quanto aquele que ela tomou para se matar. É interessante notar que a literatura-veneno consumida por Emma é justamente o "romance romântico", movimento que

3 Ema lera Paulo e Virgínia, sonhara com a cabana de bambus, com o preto Domingos, com o cão Fiel e, principalmente, com a doce amizade de algum irmãozinho [...] Quisera viver nalgum velho solar, como aquelas castelãs de corpete compridos que, sob os ornatos de ogivas, passam os dias com o cotovelo apoiado ao peitoril e o queixo na mão, a espera de ver surgir do extremo horizonte algum cavaleiro de pluma branca, galopando num cavalo preto. (FLAUBERT, 1970, p. 34) 
Flaubert tanto critica, pois são recheados de sentimentalismo, de subjetividades. Olds (2009) nos alerta, entretanto, que foi Flaubert e não Emma que leu demais, embora tenha sido ela que sofreu as consequências desse ato.

Para Aurégan (1991), Emma procura ir além dos limites da imaginação impostos pelo real. Por ocupar um lugar marginal na vida social, e se ver privada de todo o poder econômico e político, ela busca fugir dessa sua condição através da leitura dos romances e das personagens românticas que ali adquirem vida:

Avant qu'elle se mariât elle avait cru avoir de l'amour ; mais le bonheur qui aurait dû résulter de cet amour n'étant pas venu, il fallait qu'elle se fût trompée, songeait-elle. Et Emma cherchait à savoir ce que l'on entendait au juste dans la vie par les mots de félicité, de passion et d'ivresse qui lui avaient paru si beaux dans les livres. (FLAUBERT, 1951, p. 322). ${ }^{4}$

De acordo com o ponto de vista de Llosa (1979), Emma quer gozar. Ela não se resigna a reprimir em si essa profunda exigência sensual que Charles não pode satisfazer. A personagem quer cercar sua vida de elementos supérfluos, de elegância, de refinamento, busca materializar em objetos o apetite de beleza que fizeram brotar nela sua imaginação, sensibilidade e leituras. Inicialmente, Emma deseja conhecer outros mundos, outras pessoas pela literatura. Ela quer que sua existência seja diferente e excitante, que nela figurem a aventura e o risco, os gestos teatrais e magníficos da generosidade e do sacrifício, enfim, um mundo espelhado pela ficção:

Gosto da ambivalência de Ema, que, assim, como planeja com frieza audácias e excessos, emociona-se

4 Antes de se casar, julgara sentir amor; mas, como a ventura resultante desse amor não aparecia, com certeza se enganara, pensava ela. E procurava saber qual era, afinal, o significado certo, nesta vida, das palavras 'felicidade', 'paixão', e 'embriaguez', que nos livros pareciam tão belas. (FLAUBERT, 1970, p. 32) 
como uma pateta com leituras ingênuas, sonha com países exóticos de cartão postal adornados de todos os lugares comuns da época, presenteia o homem que ama com um sinete que diz Amor nel cor, pede-lhe 'à meianoite pense em mim' e pronuncia às vezes essas grandes frases ('Não há deserto, precipício ou oceano que eu não atravesse contigo. ${ }^{5}$ (LLOSA, 1979, p. 22)

Parece-nos que é exatamente o que faz Flaubert em Madame Bovary. Com isso em mente, o autor, apresenta Emma como personagem vítima de ficções, que lia romances românticos, tentando não deixar marcas de que ela própria é feita de ficção. De heroínas de romances dos séculos XVIII e XIX, Flaubert criou uma anti-heroína leitora. Daí, talvez, a razão do fim trágico de Emma, ao invés de romântico.

\subsection{Ethos de Emma provinciana}

Segundo Gaultier, não são somente os romances românticos os responsáveis na construção do ethos de Emma, sua origem provinciana também o é (apud PALANTE, 2008). Posição semelhante é a de Butor, segundo o qual, Emma Bovary "[...] ce n'est qu'une fille de campagne, son personnage va se creuser sous les yeux de Charles. Elle a des remarques qui ne sont pas celles de son milieu, parce qu'elle a eu une instruction meilleure que la plupart de ses campagnes. Cela aurait dû l'armer pour être heureuse." $(2005, \text { p. } 86)^{6}$

Relembrando que o título Madame Bovary : Mœurs de province nos remete à origem de Emma - a província -, e aos

5 FLAUBERT, 1970, p. 151

$6[\ldots]$ é apenas uma garota do campo, sua personagem vai crescer sob os olhos de Charles. Ela faz observações que não fazem parte do seu meio, porque ela teve uma educação melhor do que a da maioria de suas conterrâneas. Isso deveria ter bastado para que ela fosse feliz. 
modos como ela vive. O título marca uma relação simbólica e dicotômica entre os lugares que ela nasceu, viveu e conheceu Tostes, Yonville, Rouen -, e o que ela sonha conhecer e viver e morrer - Paris. Temos, assim, que essas dicotomias ajudam a delinear seu ethos de interiorana.

Blix (2009) também vê a condição de interiorana de Emma como uma marca de todo o seu histórico de vida. Se ela definha, por exemplo, a causa "était dans quelque influence locale" (FLAUBERT, 1951, p. 352), uma ideia que Emma compartilha quando deixa Tostes para se estabelecer em Yonville, uma vez que ela "ne croyait pas que les choses puissent se représenter les mêmes à des places différentes." (FLAUBERT, 1951, p. 369). De acordo com essa leitura romântica, sua tragédia teria nascido em um estrato social que não se adequava à excelência de sua alma. A impressão de Rodolphe poderia, obviamente, apoiar essa tese: “d'où diable sort-elle?” (FLAUBERT, 1951, p. $410)^{7}$ ele se pergunta ao achar que ela tem "la tournure comme une Parisienne" (FLAUBERT, 1951, p. 410) ${ }^{8}$. Homais, por sua vez, enfatiza, de maneira semelhante, a crescente distância entre ela e sua condição atual, quando ele acha que ela "ne serait pas déplacée dans une sous-préfecture." (FLAUBERT, 1951, p. $389)^{9}$

Gengembre (1990) afirma que Emma é uma mulher superior e, ao mesmo tempo, a insere, em pé de igualdade, às demais de sua época, todas ideologicamente e imaginativamente alienadas por sua educação, excluídas da vida pública, da produção econômica (exceto as operárias ou as camponesas), dos poderes de decisão. São todas elas mulheres (com o agravante de serem

\footnotetext{
De onde diabo veio ela? (FLAUBERT, 1970, p. 102)

$8[\ldots]$ o ar de uma parisiense (FLAUBERT, 1970, p. 102)

9 [...] não estaria deslocada numa subprefeitura (FLAUBERT, 1970, p. 85)
} 
interioranas), condenadas à submissão, à vida medíocre, ao domínio patriarcal e severo. Desprovidas de projeto de vida, elas esperam o tempo passar, as estações irem e virem, esperam, enfim, por um evento improvável, algo que lhes traga alegria de viver. O casamento, para essas mulheres provincianas, é um negócio de ingênuos, que se torna particularmente virulento em uma camada da classe social em transição com o advento da Revolução Industrial. As mulheres vivem, nesse contexto, todo tipo de drama, e Emma não foge à regra. Sob tais condições, o ethos de Emma é delineado como mulher, provinciana, pequenoburguesa, imagem que afetará sua condição de esposa e mãe, ou seja, seu ethos familial.

\subsection{Ethos familial de Emma}

Partimos do pressuposto de que qualquer leitor, na medida em que lê Madame Bovary, percebe que o ethos de mãe da personagem Emma é negativo. Dito de outra maneira, apreendemos, da leitura desse romance, que Emma, desde a gestação de Berthe, tem dificuldades em aceitar a maternidade, rejeita a filha e até mesmo a maltrata.

Para Llosa (1979), Emma sente um misto de indiferença e franco desgosto pela maternidade. Ela tem consciência clara da situação de inferioridade em que se acha a mulher na sociedade provinciana do século XIX, e isso fica evidente quando engravida. Madame Bovary deseja ardentemente que o filho seja homem "et cette idée d'avoir pour enfant un mâle était comme la revanche en espoir de toutes ses impuissances passées." (FLAUBERT, 1951, p. 371). ${ }^{10}$

$10[\ldots]$ esta idéia de ter um filho varão era como que a desforra, em esperança, de todas as suas impotências passadas. (FLAUBERT, 1970, p. 72) 
Cabe registrar que Emma trata sua filha, ainda no ventre, como "feto", demonstrando, por um lado, o jargão médicocientífico de Flaubert, e por outro lado, a falta de qualquer conotação afetiva por parte da mãe. A própria escolha do nome "Berthe" assinala a especificidade do (des)vínculo da relação mãe-filha. O nome é dado em memória de sua noite em Vaubyessard onde "elle avait entendu la marquise appeler Berthe une jeune femme" (FLAUBERT, 1951, p. 373). ${ }^{11} \mathrm{O}$ nome e a própria filha representariam, assim, apenas o veículo das aspirações de Emma, intermediários que incorporam suas fantasias.

Berthe, desde o nascimento, passa a ser um peso na vida de Emma: "elle apparait donc comme un avorton, comme un personnage resté au stade embryonnaire" (DROUET, 2009, p. 56) ${ }^{12}$. A criança está sempre doente, com cólicas e tosse incessante, tem dificuldades de aprendizagem e chora sem parar. O distanciamento para com a filha leva Emma a não a reconhecer, a ver como uma estranha e uma estrangeira. Ainda segundo Drouet (2009, p. 56-59), o estranhamento se dá por espelhamento, ou seja, Emma, ao ver a filha como alguém estranho e estrangeiro, também ela é vista dessa forma: "Emma aussi s'en est inquiété au point de se demander si sa fille n'était pas une étrangère. [...] L'étrangeté de Berthe signale donc Emma comme étrangère". ${ }^{13} \mathrm{O}$ estranhamento também é causado pela feiura da criança. O romance apresenta uma cena na qual Emma mostra-se atormentada pelo carinho da filha e a empurra

$11[\ldots]$ ouvira a marquesa chamar uma jovem de Berta (FLAUBERT, 1970, p. 73).

12 Berthe é vista, assim, como um aborto, como uma personagem que permanece em estado embrionário.

13 Emma também se preocupou ao ponto de se perguntar se sua filha não era uma estranha [...]A estranheza de Berthe, sinaliza, assim, Emma como uma estranha. 
contra o armário. Nesse momento, Emma constrói a seguinte reflexão: "C'est une chose étrange, comme cette enfant est laide !" (FLAUBERT, 1951, p. 396). ${ }^{14}$

Além de querer encarnar, teatralmente, o ethos de mãe ideal, que adora sua filha, Emma também deseja assumir o ethos de boa esposa, de mulher fiel. Cabe registrar que, em 1802, corroborado pela Igreja, o Código Civil francês define o estatuto de cidadão e reafirma a submissão da mulher ao pai e ao marido. A mulher casada não tem direitos: deve solicitar a permissão do marido até para trabalhar. Obviamente, lhe era vedado qualquer papel na política: o direito de voto passou a ser concedido às mulheres francesas apenas em 1945. Uma mulher casada, diante da lei e dos costumes, deveria ater-se em cuidar da casa, assegurar a felicidade do marido e a educação dos filhos.

O modo de existência de Emma (e das demais mulheres) é socialmente delineado, estipulado, obrigando-a a ser, a viver, a se ver de acordo com as normas estabelecidas. A imagem que ela cria / tem de si (e dos outros) é, desse modo, condicionada ideologicamente. Emma terá muitas dificuldades de sobreviver nesse contexto, de aceitar essas condições. Vemos que, como ela não consegue se adequar a seu tempo e a seus modos, ela é julgada e condenada.

Segundo Ernst (2009), tanto para Emma quanto para Charles, o conhecimento sobre o amor é problemático. Se, por um lado, Emma não sabe o quanto Charles a ama, por outro, também Charles não sabe o quanto sua esposa é incapaz de amálo. Entretanto, Emma, por um tempo, tenta amar seu marido: "Elle se demanda pourquoi elle exécrait Charles, et s'il n'eût été meilleur de le pouvoir aimer. Mais il n'offrait pas grande

14 Que coisa estranha, como é feia esta criança! (FLAUBERT, 1970, p. 92) 
prise à ces retours du sentiment, si bien qu'elle demeurait fort embarrassée dans sa velléité de sacrifice." (FLAUBERT, 1951, p. 450). ${ }^{15}$ Lattre é mais severo em seu julgamento, ou melhor, em seu delineamento do ethos de Emma, não só enquanto esposa, mas também enquanto mãe e cidadã. Para o autor:

Elle ne comprend rien. Elle n'est pas du monde où se forme sa vie. Elle est de quelque part et qui n'a pas sa part. En porte à faux. Sur tout : sur sa vie conjugale dont elle n'a pas d'idée ; sur ses tendresses maternelles dont elle ne sent rien ; sur ses exaltations qui ne connaissent pas d'écho. [...] Une bête affolée qui se heurte à toutes le vitres [...] (LATTRE, 1980, p. 12). ${ }^{16}$

Emma abomina tudo o que lhe é próximo: seu marido, sua filha, sua cidade, seus vizinhos, enfim, a sociedade a qual ela pertence. $\mathrm{O}$ fato de não aceitar tudo isso acabará por levá-la à condição de estranha e estrangeira, condição essa que a faz adoecer.

\subsection{Ethos de Emma doente}

Como vimos, Emma tem dificuldades em se adaptar a esse contexto sociohistórico do século XIX, no qual, no interior da França, as mulheres tinham seus direitos cerceados pela sociedade patriarcal. Com o destino dessas mulheres sob o controle do pai e do marido, não lhes restava muita esperança de uma vida feliz, visto que seus direitos eram limitados. Emma,

15 Perguntava mesmo de si para consigo a razão por que detestava Carlos, e se não fora melhor poder amá-lo. Mas ele não dava ocasião para aquela recrudescência do sentimento, de modo que ela ficava muito embaraçada, com os seus desejos de sacrifício (FLAUBERT, 1970, p. 133).

16 Ela não entende nada. Ela não pertence ao mundo onde sua vida se dá. Ela pertence a um outro lugar, que não é o seu lugar. Arrisca-se em tudo: em sua vida conjugal da qual ela não tem nenhuma ideia; em suas ternuras maternais nas quais ela não sente nada; em suas exaltações que não encontram eco. [...] Uma besta em pânico que não enxerga um palmo à frente do nariz [...] 
não suporta a condição de esposa e de mãe além de não aceitar o fato de ser interiorana. Uma das tentativas de saída encontrada pela personagem para escapar dessas condições foi a leitura de romances românticos. Entretanto, ela não consegue se satisfazer e se sente infeliz:

Elle n'était pas heureuse, elle ne l'avait jamais été. D'où venait donc cette insuffisance de la vie, cette pourriture instantanée des choses où elle s'appuyait ? [...] Oh quelle impossibilité ! Rien d'ailleurs ne valait la peine d'une recherche, tout mentait ! Chaque sourire cachait un bâillement d'ennui, chaque joie une malédiction, tout plaisir un dégoût et les meilleurs baisers ne vous laissaient sur la lèvre qu'une irréalisable envie d'une volupté plus haute. (FLAUBERT, 1951, p. 550). ${ }^{17}$

Seu desajuste, sua tristeza e sua infelicidade a levam a adoecer. Emma tem ataques de nervos, desmaios, perda de apetite. A personagem não suporta mais a vida em Tostes e quer se mudar, pois acredita que encontrará a felicidade em outro lugar, em uma cidade maior. Ela tenta convencer Charles, e, para incentivá-lo a mudar de cidade, ela "but du vinaigre pour se faire maigrir, contracta une petite toux sèche et perdit complètement l'appétit." (FLAUBERT, 1951, p. 352).

Em um outro episódio, nos deparamos, mais uma vez, com a instabilidade emocional da Senhora Bovary. Na época do rompimento com Rodolphe, quando ela vê seu tilbury azul atravessar a praça, ela "poussa un cri et tomba roide par terre, à la renverse" (FLAUBERT, 1951, p. 481) ${ }^{18}$ e teve "le long du corps des mouvements convulsifs" (FLAUBERT, 1951, p.

17 [...] não era feliz, nunca o fora. De onde vinha, pois, aquela insuficiência da vida, aquele apodrecimento instantâneo das coisas em que se apoiava? [...] Que impossibilidade! Nada, afinal, valia a pena procurar-se; tudo metia! Cada sorriso ocultava um bocejo de enfado, cada alegria uma maldição, todo prazer o seu desgosto, e os melhores de todos os beijos não deixavam nos lábios senão uma irrealizável ânsia de voluptuosidades mais intensas. (FLAUBERT, 1970, p. 213-214)

18 [...] soltou um grito e caiu no solo, de bruços (FLAUBERT, 1970, p. 157). 
481). ${ }^{19}$.Mais tarde, durante uma discussão com sua sogra sobre a procuração que tinha obtido de Charles, Emma "se mit à rire d'un rire strident, éclatant, continu : elle avait une attaque de nerfs" (FLAUBERT, 1951, p. 542). ${ }^{20} \mathrm{O}$ estado de saúde frágil de Bovary ajuda a compor seu ethos. Para alguns críticos, ela será considerada apenas uma pessoa infeliz e doente, para outros, ela se encaixa perfeitamente no diagnóstico de histérica, e ainda para outros estudiosos da obra, ela sofrerá de bovarismo.

Vatan (2009) observa que os tratados médicos da época que descreviam a histeria listam uma série sintomas facilmente identificáveis e relacionados aos problemas de Emma: nervosismo, alterações de humor, desmaios, desejos incomuns, espasmos, sensação de asfixia e estrangulamento, riso súbito, torrentes de lágrimas, estados de prostração e convulsões, etc. Encontramos, em diversas passagens do romance, descrições dos estados físicos e emocionais de Emma, que nos ajudam a construir esse seu ethos de mulher doente, instável, nervosa e histérica. Emma, depois de sofrer diversas desilusões no casamento, nos relacionamentos com seus amantes, em sua vida social e financeira, tornou-se

[...] difficile, capricieuse, ne buvant un jour que du lait pur, et, le lendemain, des tasses de thé à la douzaine. Souvent elle s'obstinait à ne pas sortir, puis elle suffoquait, ouvrait les fenêtres, s'habillait en robe légère. [...] Elle bavardait avec une abondance fébrile à ces exaltations succédait tout à coup des torpeurs où elle restait sans parler, sans bouger [...] Elle pâlissait et avait des battements de cœur. Charles lui administra de la valériane et des bains de camphre. Tout ce que l'on essayait semblait l'irriter davantage. (FLAUBERT, 1951$, p. 351-352) $)^{21}$

$19[\ldots]$ movimentos convulsivos ao longo do corpo (FLAUBERT, 1970, p. 157).

20 Emma desatou a rir com um riso estridente, agudo, contínuo; tinha um ataque de nervos (FLAUBERT, 1970, p. 207).

$21[\ldots]$ difícil, caprichosa [...] um dia bebia apenas leite simples e no seguinte chávenas de chá às dúzias. Muitas vezes teimava 
Apesar de não encontramos no romance e tampouco na Correspondance de Flaubert nenhuma referência explícita, nenhuma utilização da palavra "histeria", o autor registra o dilaceramento de uma mulher acometida por uma inspiração dolorosa a um mundo inacessível, aspiração sinônima de discordância entre o sonho e a realidade. Essa é, por excelência, a definição de histeria.

Ainda relativo à saúde de Emma, Gaultier, em 1902, criou o termo bovarysme, em um artigo que trata de algumas características comportamentais de Emma Bovary e as classifica como sintomas de uma doença psicológica. Segundo o estudioso,

\begin{abstract}
Ainsi ce qui est typique en Madame Bovary, c'est bien ce pouvoir de se concevoir autre, idéalisé chez elle jusqu'à constituer sa véritable personnalité et confondu avec la haine de toute réalité à ce point que ces deux éléments, cause et effet l'un de l'autre, inscrivent un cercle où tous ces actes aboutissent. (GAULTIER apud PALANTE, 2008, p. 68 $)^{22}$
\end{abstract}

Emma imagina-se outra pessoa, diferente daquilo que ela realmente é. Podemos ver, ao longo da obra, que Emma estabelece relações com as outras personagens sempre marcadas por uma teatralização de sua voz, seus gestos e suas atitudes. Ela acredita ser as heroínas românticas dos romances que lê. Semelhante aos papéis sociais de que nos fala Charaudeau (2006a), a cada momento, Emma “encarna” papéis, personalidades diferentes tais como esposa fiel, leitora sonhadora, mulher devota, heroína

em não sair, depois sentia-se sufocada, abria as janelas, vestia uma roupa leve [...] As vezes tagarelava com uma abundância febril a estas exaltações sucediam torpores repentinos, em que permanecia sem falar e sem se mover [...] Empalidecia e tinha sobressaltos de coração. Carlos ministrou-lhe valeriana e banhos canforados, mas tudo quanto lhe davam parecia irritá-la ainda mais. (FLAUBERT, 1970, p. 55-56)

22 Assim, o que é típico em Madame Bovary, é esse poder de se imaginar outro, idealizado nela a ponto de constituir sua verdadeira personalidade e, confundido com o ódio a toda a realidade a ponto que esses dois elementos, causa e efeito um do outro, instalem um círculo onde todos esses atos se concluem. 
trágica, a castelã que aguarda seu príncipe, a nobre que dança com o visconde no baile... Ela parece não enxergar que é uma mulher da província, limitada e sem recursos. Sua maneira de viver indica que ela acredita ser alguém que pertence ao mundo dos contos de fadas.

Com o bovarismo temos, assim, uma patologia, um desvio psicológico cujo nome remete à personagem de Flaubert. Doença diagnosticada em pessoas incapazes de perceber a realidade circundante comum, cotidiana, ou, se a percebe, não a aceita, busca outras realidades e gasta toda energia nessa busca.

\subsection{Ethos de Emma religiosa}

A educação de Emma é tema frequente nos estudos sobre romance Madame Bovary. Ela foi educada em um convento de Rouen e essa experiência, além de marcá-la por toda vida, é fundamental na construção de seu ethos. Suas ações, seus pensamentos, enfim, sua visão de mundo, foram construídos dentro do convento, onde recebeu uma esmerada educação religiosa. Dessa forma, seu ethos de mulher educada e / ou de mulher que recebeu educação superior a suas conterrâneas, aparece nos vários artigos críticos sobre o romance e sobre sua personagem principal. Há várias passagens no romance que comprovam que Emma segue a maioria dos sete sacramentos da igreja católica, a saber: o batismo (capítulo III, parte II), crisma e eucaristia (capítulo XIV, parte II), penitência (capítulo VI, parte I), extrema-unção (capítulo VIII, parte III), e matrimônio (capítulo IV, parte I).

As bibliotecas a que Emma tem acesso são compostas de 
obras científicas, religiosas e literárias. Não se interessando pela literatura médica, a personagem toma obras religiosas como objeto de leitura romanesca e vice-versa, ambas alimentam as fantasias e os devaneios da personagem. Como já dito, as leituras de Emma evidentemente fazem parte de sua educação e ajudam na construção de seu ethos. Segundo Gengembre,

Le couvent et les lectures constituent une structuration de l'expérience de la petite fille puis de l'adolescence. Un mixte de mysticisme et d'amour se crée à partir des langueurs éthérées, des confessions, de l'amant céleste : sensualisme et spiritualisme se mêlent dès lors inextricablement. Si le couvent est bien un enfermement, il est contaminé, délicieusement, par un monde extérieur rêvé, imaginé, lu. (GENGEMBRE, 1990 , p. 56-57 $)^{23}$

Essa mistura de sentimentos, profanos e sagrados, por parte de Emma, é descrita em diversas passagens do romance. Quando ela está no convento e participa da missa, por exemplo, ela divaga e "Les comparaisons de fiancé, d'époux, d'amant céleste et de mariage éternel qui reviennent dans les sermons lui soulevaient au fond de l'âme des douceurs inattendues." (FLAUBERT, 1951, p. 323) Além disso, quando Emma ia confessar-se, “elle inventait de petits péchés, afin de rester là plus longtemps, à genoux dans l'ombre, les mains jointes, le visage à la grille sous le chuchotement du prêtre." (FLAUBERT, 1951, p. 323). ${ }^{24}$

23 A educação de Emma, tantas vezes comentada, é um bom exemplo do determinismo. O convento e as leituras são uma estruturação da experiência da infância e depois da adolescência. Uma mistura de misticismo e amor são criados a partir da languidez etérea, das confissões, do amante celestial: sensualismo e espiritualismo se misturam inextricavelmente. Se o convento é uma clausura, ele está deliciosamente contaminado, por um mundo exterior sonhado, imaginado, lido. Emma, a versão feminina de Don Quixote, transforma a realidade em ficção, tornando-se um romancista fracassado, uma frustrada, que as letras tentarão satisfazer.

$24[\ldots]$ inventava pecadinhos, para se demorar mais tempo de joelhos, na sombra, com as mãos postas e o rosto colado ao 
Contudo, vale destacar que, de acordo com Dord-Crouslé (2009), Emma, depois de sair do convento, não se interessa mais à devoção. Ao voltar para casa, ela não segue mais os ditos da igreja. É preciso esperar a crise mística do final da segunda parte do romance para ela reencontrar algum interesse pelas coisas espirituais. Emma procura a Igreja e o padre Bournisien para se reconfortar devido às decepções amorosas. Após a fuga de Rodolphe, Emma deambula desesperada e fica doente ao ponto de achar que vai morrer e pede a comunhão. O sacramento the dá alívio imediato, e para cultivar as delícias e prazeres que encontrou, ela ambiciona a santidade.

Podemos perceber, assim, que Emma, ao buscar ajuda mística, o faz através de novos consumos e de novos prazeres. Segundo Gengembre (1990, p. 60), ao se recolher na igreja, "Elle tire du lieu même un plaisir accru". ${ }^{25}$ Emma vê a catedral como um imenso boudoir, cheio de prazeres celestiais e de luxo abundante. Dessa forma, delineamos, em mais uma etapa, o ethos da personagem: Emma-religiosa, Emma-profana...

\subsection{Ethos de Emma burguesa}

Emma busca a religião para curar seu amor, para encontrar conforto para suas desilusões, mas também, e, sobretudo, pelo seu luxo, pelo luxo da ostentosa catedral de Rouen e pelo prazer que as aquisições materiais the proporcionam. O consumo de bens religiosos oferece à personagem grande satisfação somente por um tempo. Não se satisfazendo com o consumo do que o religioso lhe oferece, Emma entra em um novo ciclo de consumo, 
onde as insatisfações sentimentais e sexuais serão, acredita ela, compensadas. O prazer, porém, continuará muito fugaz. Logo lhe surge uma inquietação que a leva a consumir cada vez mais.

Percebemos que, desdea infância de Emma, suas dificuldades financeiras, sua queda para o consumo, seu descontrole com seus gastos é tema recorrente no romance e também nos estudos sobre a obra. Sua educação, seu casamento e, por fim, seus gastos excessivos, que a levam ao suicídio, compõem a linha que guia a vida de Madame Bovary. Nos estudos de Aurégan, temos, resumidamente, essa linha da vida de Emma guiada pelo dinheiro:

Emma, fille d'un 'cultivateur aisé', est élevée comme une bourgeoise et nourrit des aspirations bien au-dessus de sa condition. Leur mariage [celui avec Charles] est déterminé par des nécessités économiques, qui poussent le père Rouault à marier sa fille, sans dot, à un modeste officier de santé. Ainsi la ruine des Bovary ne relève pas de sa responsabilité individuelle d'Emma mais résulte d'une situation sociale bâtarde. (AUREGAN, 1991, p. $40)^{26}$

Com base nessa descrição, podemos dizer que Emma passa sua vida tentando adquirir algo para compensar suas frustrações. Ela consome até Charles não ter mais dinheiro, até levá-lo à falência. De acordo com Gengembre (1990), ela não se permite parar de consumir, pois se ela para de comprar é porque o dinheiro acaba, e aí vem sansão imposta pela coerção social. Emma demonstra, com suas ações, se sentir superior e mais nobre que seus conterrâneos provincianos burgueses preocupados com seus

26 Emma, filha de um 'agricultor rico', é criada como uma burguesa e nutre aspirações muito acima de sua condição. Seu casamento [com Charles] é determinado por necessidades econômicas, que levam o pai Rouault casar com sua filha, sem dote, com um oficial de saúde modesto. Assim, a ruína dos Bovary não advém da responsabilidade individual de Emma, mas é o resultado de uma situação social bastarda. 
gastos. Ela se recusa a se restringir e "ne s'inquiétait pas plus de l'argent qu'une archiduchesse" (FLAUBERT, 1951, p. 550). ${ }^{27} \mathrm{~A}$ atitude de Emma de comprar desenfreada e irresponsavelmente mostra seu ethos de consumista e essa sua atitude a levará à falência e ao suicídio.

O dinheiro é, então, no romance, de importância capital. Ele dá vida, justifica a existência de, por exemplo, Monsieur Lheureux. Ele determina o casamento de Emma, mantem sua relação com seus amantes, delimita as condições e as relações sociais, marca o destino de Emma, sua morte. Juntamente com as leituras, com os amantes, o dinheiro é, para Emma, um meio de acesso aos sonhos, ao universo do imaginário, à felicidade, mas também à sua queda.

Nessas circunstâncias, Lattre (1980) descreve Emma como uma mulher do interior que não suporta ter uma vida de pequeno-burguesa e deseja desesperadamente uma ascensão social. Ainda segundo o autor, a frenética aquisição de objetos inúteis, a acumulação de pequenas coisas que lhe dão prazer estético como, por exemplo, os papéis de carta que ela nunca usa, os tecidos que ficam guardados na gaveta, é consumo sem objetivo, gastar por gastar, pelo prazer de possuir, a busca pelo ter ao invés da busca pelo ser.

Gengembre (1990), por sua vez, acredita que a personagem consome incessantemente não para tirar proveito material, para ostentar, para manter um mundo de aparência, como é típico dos burgueses, mas sim para suprir uma falta afetiva, numa relação fetiche com os objetos sustentada pela emoção e pela sensualidade. Os objetos enquanto tal não the proporcionam o gozo, mas sua relação sentimental e sensual com tudo aquilo que ele representa: o luxo, a nobreza, os amantes...

$27[\ldots]$ não se preocupava mais por dinheiro que uma arquiduquesa (FLAUBERT, 1970, p. 214) 
Como tema essencialmente burguês, o dinheiro, que proporcionaria a compra da felicidade e da liberdade de Emma, se mostra, então, paradoxalmente, como aquele que provocará em Emma um grande confinamento: a provinciana que não queria ser burguesa, mas sim nobre, age de maneira burguesa. Seus valores são burgueses, seu consumo para alimentar seus devaneios a confinam na pior convenção do casamento burguês. Emma não sabe dar valor ao dinheiro, joga com ele, ou como assevera Llosa: "parece comovedor que Ema, quando o mundo começa a lhe cair em cima, gaste os últimos cinco francos atirando-os a um mendigo.” (LLOSA, 1979, p. 22)

\subsection{Ethos de Emma adúltera}

Apesar de Charles demonstrar e dizer em vários momentos que ama sua esposa, temos a impressão de que Emma nunca o amou. A imagem de Emma para Charles é de uma mulher perfeita, boa esposa, boa mãe. Entretanto, é recorrente no romance o ethos de Charles, construído por Emma, quase sempre de maneira negativa. Ela chega a se questionar porque casou com ele: "Pourquoi, mon Dieu, me suis-je mariée?" (FLAUBERT, 1951, p. 331). ${ }^{28}$ Infeliz no casamento, Emma procura uma saída para suas desilusões matrimoniais. Ela acredita que o adultério pode lhe proporcionar prazer, gozo, tudo aquilo que ela não encontrou com/em Charles.

A personagem, que não é livre enquanto mulher, tampouco enquanto burguesa, vê, no adultério, sua única solução, o caminho para a felicidade. Desse modo, o adultério é de extrema importância na estruturação do romance e no delineamento do ethos da

28 Mas, meu Deus! Para que me casei? (FLAUBERT, 1970, p. 40) 
personagem. Mas, nem mesmo nas relações extraconjugais, Emma se realiza. Com o tempo, "Emma retrouvait dans l'adultère toutes les platitudes du mariage" (FLAUBERT, 1951, p. 556). ${ }^{29}$

Com Rodolphe como amante, temos um jogo de sedução e performance eróticas. Ela é um corpo desejante e desejável que será, depois de usado, descartado "Elle est fort gentille! Cette femme du médecin ! Des belles dents, les yeux noirs, le pied coquet et de la tournure, comme une parisienne. [...] Oh ! Je l'aurai [...] Oui, mais comment s'en débarrasser ensuite ?" (FLAUBERT, 1951, p. 410) ${ }^{30}$. Emma, depois de trair Charles com seu amante Rodolphe, não sente remorsos:

Elle se répétait : 'J'ai un amant ! j'ai un amant !' se délectait à cette idée comme à celle d'une autre puberté qui lui serait survenue. Elle allait donc enfin posséder ces plaisirs de l'amour, cette fièvre de bonheur dont elle avait désespéré. Elle entrait dans quelque chose de merveilleux, où tout serait passion, extase, délire. (FLAUBERT, 1951, p. 439)

Flaubert, ao descrever Emma durante seus encontros amorosos com outros homens diz que: "Jamais Mme Bovary ne fut aussi belle qu'à cette époque ; elle avait cette indéfinissable beauté qui résulte de la joie, de l'enthousiasme, du succès, et qui n'est que l'harmonie du tempérament avec les circonstances." (FLAUBERT, 1951, p. 469). ${ }^{31}$

Com o tempo, o ethos de Emma delineado por Rodolphe sofre um deslocamento. Para ele, "Emma ressemblait à toutes les maîtresses ; et le charme de la nouveauté, peu à peu tombant

29 Ema reencontrava no adultério toda insipidez do lar conjugal. (FLAUBERT, 1970, p. 218)

30 É encontadora essa mulher do médico! Belos dentes, olhos negros, pé elegante e o ar de uma parisiense. [...] mas como desembaraçar-se dela, depois? (FLAUBERT, 1970, p. 102)

31 Nunca a Sra. Bovary fora tão bela como então; tinha essa inexprimível beleza que resulta da alegria, do entusiasmo, do êxito, e que nada mais é que a harmonia do temperamento com as circunstâncias. (FLAUBERT, 1970, p. 148) 
comme un vêtement, laissait voir à nu l'éternelle monotonie de la passion, qui a toujours les mêmes formes et le même langage." (FLAUBERT, 1951, p. 466). ${ }^{32}$ A relação extraconjugal termina com a fuga de Rodolphe, que envia à amante uma carta de despedida.

Emma, decepcionada, procura um segundo amante. Veremos que, tanto Léon, quanto Rodolphe, seguem um projeto paralelo e parecido: sedução, prazer, monotonia, desgaste e desilusão, que Emma tenta compensar com possessividade e consumo. Léon representa para Emma o mundo da literatura, dos teatros, dos concertos. No início, tudo era como Emma desejava e ela se entregava totalmente a seu amante: "Quel débordement, le jeudi d'après, à l'hôtel, dans leur chambre, avec Léon ! Elle rit, pleura, chanta, dansa, fit monter des sorbets, voulut fumer des cigarettes, lui parut extravagante, mais adorable, superbe." (FLAUBERT, 1951, p. 542). ${ }^{33}$

Depois desse início romântico, vieram os problemas: "Emma attendit Léon trois quarts d'heure. Enfin elle courut à son étude, et, perdue dans toute sorte de conjectures, l'accusant d'indifférence et se reprochant à elle-même sa faiblesse, elle passa l'après-midi le front collé contre les carreaux." (FLAUBERT, 1951, p. 546). Houve um momento em que Léon afastou-se de Emma e jurou a si mesmo não se encontrar mais com sua amante, repreendia-se, porém, de não ter cumprido sua palavra e lembrou-se dos inúmeros embaraços que ela ainda poderia the causar. Assim como Rodolphe, Léon faz o mesmo questionamento: "Mais comment pouvoir s'en débarrasser ?" (FLAUBERT, 1951, p. 556). ${ }^{34}$

32 Ema parecia-se às demais amantes; e o encanto da novidade, caindo aos poucos como um vestido, exibia a eterna monotonia da paixão, sempre da mesma forma e da mesma linguagem. (FLAUBERT, 1970, p. 146)

33 Que expansão, na quinta-feira seguinte, no hotel, no quarto, com Léon! Ela riu, chorou, cantou, dançou, mandou buscar sorvetes, quis fumar charutos, pareceu-lhe extravagante, mas adorável, soberba. (FLAUBERT, 1970, p. 208)

34 Mas como desembaraçar-se? (FLAUBERT, 1970, p. 218) 
Emma não consegue lidar com o adultério como uma segunda vida: ela pensa ser a verdadeira, a única existência gratificante. Atraída pelo desejo do absoluto, ela não consegue entender o elo necessário que une o casamento e sua transgressão. Ela se condena três vezes: pela escolha dos amantes, que integram o adultério em seu plano de carreira e os trata de acordo com as convenções sociais, pela insatisfação com sua paixão, pela sua recusa do estatuto de mulher casada.

Se para muitos, Emma é apenas uma mulher adúltera, para Baudelaire, ela é "la victime déshonorée, possède toutes les grâces du héros" (BAUDELAIRE, 1948, p. 239-240)35. Ainda para Baudelaire, "Quelle est la femme qui, devant cette insuffisance du curé, n'irait pas, folle amnistiée, plonger sa tête dans les eaux tourbillonnantes de l'adultère ?" (BAUDELAIRE, 1948, p. 244-245). ${ }^{36}$

Emma morre não por ser adúltera, mas, sobretudo, por não conseguir pagar suas dividas: "elle ne se rappelait point de la cause de son horrible état, c'est-à-dire la question d'argent" (FLAUBERT, 1951, p. 577). No seu leito de morte, ela compreendeu toda a sua existência. Ela sabe que a desperdiçou, a perdeu, por falta de ter sabido reconhecer seus limites. Sua morte, por ser voluntária, se torna absurda. O fato de Emma cometer suicídio a leva à verdadeira grandeza trágica: ela não é mais confundida na legião das mulheres adúlteras, ela se eleva acima do mundano e do pobre destino da promiscuidade. Enfim, aqueles que mataram Emma são os mesmos que lhe deram vida, aqueles que forjaram sua imagem, seu caráter, enfim, seus ethé: Flaubert, Charles, Rodolphe, Léon, as personagens românticas, a crítica, a Justiça, a sociedade, todos nós leitores...

$35[\ldots]$ a vítima desonrada, possui todas as graças do herói.

36 Qual é a mulher que, diante da insuficiência do padre, não iria, perdoada, mergulhar a cabeça no turbilhão das águas do adultério? 


\section{Considerações Finais}

A Análise do Discurso pode ser frutífera na análise do texto literário, na (re)constituição doa imagem de si da personagem principal de um romance. Isso reafirma uma tendência recentemente observada por pesquisadores da Análise do Discurso de que “[...] pela primeira vez na história, a totalidade dos enunciados de uma sociedade, apreendida na multiplicidade de seus gêneros, é convocada a se tornar objeto de estudo" (CHARAUDEAU \& MAINGUENEAU, 2004, p. 46). Daí nosso interesse em trabalhar com o conceito de ethos no universo da Literatura, uma vez que seu alcance social merece ser considerado.

Emma, com seu jeito de ser, suas ações, gestos e expressões, sua fisionomia, enfim, a imagem de si é construída, modelada a partir dos ethos construído de outras pessoas, criando uma força de ilusão tal que toma a pessoa incapaz de distinguir (se) na / da alteridade. Podemos, então, perceber a pluralidade do ethos de Emma, de como ele é multifacetado e, principalmente, como ele funciona como um recurso retórico/argumentativo capaz de gerar vários efeitos de sentido diferenciados, segundo os valores daqueles que o lê, as ideologias e as épocas.

Pelos intertextos e interdiscursos, compomos nossa escrita. Dialogamos, interagimos com uma multiplicidade de autores. Juntos, construímos os significados. Apresentamos algumas leituras, sentidos que achamos mais plausíveis, mais evidentes e convincentes e tentamos expô-los da forma mais clara possível. Flaubert, os críticos e nós, somos, antes de tudo, leitores e, como tais, buscamos, nas escritas uns dos outros, as imagens de si. 
Nelas, (nos) lemos, a partir delas, escrevemos e nos inscrevemos, (nos) dividimos, (nos) duplicamos. As escritas nunca coincidem exatamente com as (re)leituras, (re)criações. Nesse universo de assimetrias, o discurso, o texto, a enunciação do outro não são transparentes para nenhum de nós.

\section{Referências}

AMOSSY, R. "Ethos". In: CHARAUDEAU, P. \& MAINGUENEAU, D. (org.) Dicionário de Análise do Discurso. São Paulo: Contexto, 2004.

AURÉGAN, P. Flaubert. Paris: Nathan, 1991.

BARTHES, R. Aula. São Paulo: Cultrix, 1978.

BARTHES, R. O Rumor da Língua. Lisboa: Edições 70, 1987. BAUDELAIRE, C. Euvres complètes. Vol. 4. Paris: A la Girouette, 1948.

BLIX, G. "Le Personnage et son milieu: réalisme et liberté dans Madame Bovary" In: REY, P.-L. \& SÉGINGER, G. (org.) Madame Bovary et les savoirs. Paris: Presses Sorbonne Nouvelle, 2009, p. 243-256.

BUTOR, M. Improvisations sur Flaubert. Paris: Éditions de la Différence, 2005.

CHARAUDEAU, P. Langage et Discours, Eléments de sémiolinguistique. Paris: Hachette - Université, 1983.

CHARAUDEAU, P. Prefácio. In: MELlO, R. Análise do Discurso \& Literatura. Belo Horizonte: NAD, 2005, p. 15-16. CHARAUDEAU, P. Discurso Político. São Paulo: Contexto, 2006. 
CHARAUDEAU, P. "Identidade social e identidade discursiva, o fundamento da competência comunicacional". In: PIETROLUONGO, M. (org.). O trabalho da tradução. Rio de Janeiro: Contracapa, 2009, p. 309-326.

CHARAUDEAU, P. \& MAINGUENEAU, D. (org.) Dicionário de Análise do Discurso. São Paulo: Contexto, 2004.

COMPAGnON, A. O Demônio da Teoria Literatura e senso comum. Belo Horizonte: UFMG, 2003.

DORD-CROUSLÉ, S. "Les deux bibliothèques religieuses de Madame Bovary". In: REY, P.-L. \& SÉGINGER, G. (org.) Madame Bovary et les savoirs. Paris: Presses Sorbonne Nouvelle, 2009, p. 147-155.

DROUET, G. "Du foetus au changeling : ethnocritique de Berthe". In: REY, P.-L. \& SÉGINGER, G. (org.) Madame Bovary et les savoirs. Paris: Presses Sorbonne Nouvelle, 2009, p. 55-64.

ERNST, J. "Le corps à l'épreuve des savoirs dans Madame Bovary". In: REY, P.-L. \& SÉGINGER, G. (org.) Madame Bovary et les savoirs. Paris: Presses Sorbonne Nouvelle, 2009, p. 179-187.

FIORIN, J. L. (org.) Introdução à Linguística I. Objetos teóricos. São Paulo: Contexto, 2005.

FLAUBERT, G. CEuvres Complètes. Paris: Gallimard (Pléiade, Tomo I), 1951.

FLAUBERT, G. Madame Bovary. Tradução de Araújo Nabuco. São Paulo: Editora Abril Cultural, 1970.

FLAUBERT, G. Correspondance. Paris: Gallimard (Pléiade, Tomo II), 1980.

GENGEMBRE, G. Gustave Flaubert: Madame Bovary. Paris: PUF, 1990.

JAKOBSON, R. Linguística e comunicação. São Paulo: Cultrix, 1975. 
LATTRE, A. La Bêtise d'Emma Bovary. Paris: Librairie José Corti, 1980.

LlOSA, M. V. A Orgia Perpétua. Rio de Janeiro: Francisco Alves, 1979.

MACHADO, I. L. "O charme discreto da transgressão de gêneros na poesia". In: MARI, $\mathrm{H}$ et al. (org.) Análise do Discurso em perspectivas. Belo Horizonte: NAD, 2003. p. 83-100.

MAINGUENEAU, D. "O discurso literário contra a literatura". In: MELLO, R. (org.). Análise do Discurso \& Literatura. Belo Horizonte: NAD, 2005. p. 17-29.

MAINGUENEAU, D. Discurso e Análise do Discurso. In: SIGNORINI, I. (org.). [Re] discutir texto, gênero e discurso. São Paulo: Parábola, 2008, p. 135-155.

MELLO, R. Análise do Discurso \& Literatura. Belo Horizonte: NAD, 2005a.

MELLO, R. "Análise do Discurso \& Literatura: uma interface real". In: MELLO, R. (org.). Análise do Discurso \& Literatura. Belo Horizonte: NAD, 2005b. p. 31-44.

OLDS, M. C. "Madame Bovary et l'étude de mœurs". In: REY, P.-L. \& SÉGINGER, G. (org.) Madame Bovary et les savoirs. Paris: Presses Sorbonne Nouvelle, 2009, p. 105-112.

PALANTE, G. Le Bovarysme : Une moderne Philosophie de l'Illusion. Paris: Rivages poche, 2008.

VATAN, F. "Emma Bovary : parfaite hystérique ou 'poète hystérique ?” In: REY, P.-L. \& SÉGINGER, G. (org.) Madame Bovary et les savoirs. Paris: Presses Sorbonne Nouvelle, 2009, p. 219-229. 